\title{
Novas concepções para reatores anaeróbios de manta de lodo: uso de mistura mecânica ou hidráulica com decantação lamelar e sem separador trifásico
}

\author{
New concepts for anaerobic sludge blanket reactors: the use of mechanical \\ or hydraulic mixing with high-rate settler and without three-phase separator
}

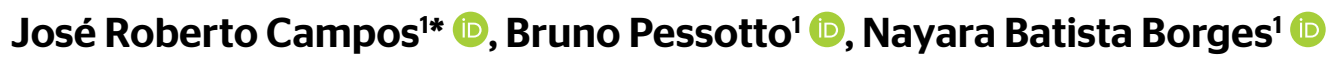

\section{RESUMO}

Neste artigo, apresenta-se uma abordagem conceitual sobre propostas de alternativas para a concepção de sistemas com reator anaeróbio de manta de lodo. Em essência, propõem-se: i) a eliminação dos separadores de gás, líquido e sólido que constam em reatores upflow anaerobic sludge blanket reactors e sua substituição por unidade de sedimentação de alta taxa em setor incluso ou externo ao volume do reator biológico; ii) a recirculação de parcela do lodo retido no sedimentador, transformando o conjunto em um sistema semelhante ao de lodo ativado, porém preservando a manta de lodo no reator anaeróbio (activated anaerobic s/udge blanketsystem) e, assim, viabilizando melhor controle do tempo de retenção celular; e iii) a simplificação (menor número de entradas) do sistema de distribuição do afluente junto ao fundo da zona de reação, mediante duas alternativas: agitação mecânica ou agitação hidráulica com jatos - em ambos os casos, intermitentes. As propostas, conforme apresentadas, constituem resumo de pesquisa baseada em reatores de bancada sucedida pela operação e testes em duas unidades-piloto paralelas (volume total: $20,8 \mathrm{~m}^{3}$, incluindo volumes de reação e de sedimentação). Constatou-se que é possivel remover sólidos suspensos do efluente da região de reação sem a necessidade do separador trifásico e, também, que é possível manter-se a manta de lodo mesmo com a agitação na região de reação. Foram obtidos bons resultados na remoção de sólidos suspensos totais, demanda bioquímica de oxigênio e demanda química de oxigênio nos sedimentadores com valores de taxa de aplicação superficial de 34,0 até 81,6 $\mathrm{m}^{3} \mathrm{~m}^{2}$ dia. Constatou-se, também, que valores bastante baixos de gradiente de velocidade ( $\mathrm{G}$ 20s') são suficientes para promover a manutenção da manta de lodo e que a intermitência na agitação é favorável ao processo biológico. Os resultados relacionados com a remoção de demanda química de oxigênio, demanda bioquímica de oxigênio e sólidos suspensos totais foram comparados com os de outros estudos sobre reatores upflow anaerobic sludge blanket reactors convencionais. Contudo, aqueles relacionados com o tempo de reação celulat foram os mais significativos para as conclusões desta pesquisa.

\section{ABSTRACT}

This paper presented a conceptual approach toward alternatives for the design of anaerobic sludge blanket reactors. In essence, it is proposed: i) the elimination of gas-liquid-solid separators that integrate the upflow anaerobic sludge blanket reactors and their replacement by a high rate settlers placed inside or outside the volume of biological reactor; ii) the recirculation of a fraction of the of the sludge retained in the settler, converting the process into a solution that resembles the activated sludge system, however, preserving the sludge blanket (Activated Anaerobic Sludge Blanket System), and thus ensuring better control of the cell retention time; and iii) the simplification (lower inlet points) of the influent distribution system placed over the bottom of the reaction zone, upon the implementation of two alternatives: mechanical mixing or hydraulic agitation with jet discharges, intermittent, in both cases. The proposals, as presented, are a summary of researches based on bench scale tests succeeded by the operation and tests in two parallel pilot units (total volume: $20.8 \mathrm{~m}^{3}$, including reaction zone and settler). It was found that it is possible to remove suspended solids from the effluent of the reaction zone without the need for a three-phase separator, and also, that it is possible to maintain the sludge blanket even with mixing in the reaction zone. Good results regarding total suspended solids, biochemical oxygen demand and chemical oxygen demand removal in the settlers were obtained, with applied hydraulic loading rate from 34.0 to $81.6 \mathrm{~m}^{3} \mathrm{~m}^{2}$ day. It was also found that very low velocity gradient values ( $£ 20 \mathrm{~s}^{-1}$ ) are required to promote the maintenance of the sludge blanket, and the intermittency in the agitation is favorable to the biological process. The results concerning, , and TSS removal were compared with those of other studies on conventional upflow anaerobic sludge blanket reactors. However, those related to sludge age were the most significant to the conclusions of this research. When the reactor

$\square$

'Universidade de São Paulo - São Paulo (SP), Brasil.

*Autor correspondente: jrcampos@sc.usp.br

Conflitos de interesse: os autores declaram não haver conflitos de interesse

Financiamento: Fundação de Amparo à Pesquisa do Estado de São Paulo (FAPESP) - número do processo no 10/518245.

Recebido: 19/04/2O2O - Aceito: 09/12/2020 - Reg. ABES: 20200146 
Quando o reator foi operado com tempo de detenção hidráulica de 8,2 h e velocidade ascensional no reator biológico de 0,69 mh'1, o tempo de reação celular do sistema resultou em 175 dias. Com velocidade ascensional menores, os valores de tempo de reação nuclear foram ainda maiores (por exemplo: velocidade ascensional = 0,39 mh'; tempo de reação celular = 363 dias). Os resultados deste trabalho abrem perspectivas para novas pesquisas e novos horizontes para projeto de sistemas com reatores anaeróbios de manta de lodo e decantadores de alta taxa

Palavras-chave: reatores UASB; sedimentação de alta taxa; separador trifásico GLS; manta de lodo; mistura em manta de lodo; lodo ativado anaeróbio. was operated with a hydraulic retention time of $8.2 \mathrm{~h}$ and a upflow velocity upflow velocity of $0.69 \mathrm{mh}^{-1}$ in the biological reactor, the average sludge age reached 175 days. When applying smaller values of upflow velocity, the sludge age values reached greater values (Example: upflow velocity $=0.39 \mathrm{mh}^{-1}$; sludge age $=363$ days). The results and conclusions of this research open new perspectives for future research and new horizons for designing systems consisting of anaerobic sludge blanket and high-rate settlers.

Keywords: UASB reactors; high-rate settlers; GLS separators; sludge blanket; sludge blanket mixing; anaerobic activated sludge.

$\square$

\section{INTRODUÇÃO}

Lettinga et al. $(1980,1981)$, com base em pesquisas efetuadas no final da década de 1970, criaram e propagaram o uso de reatores upflow anaerobic sludge blanket reactors (UASB) em países de clima tropical e subtropical. Para orientar os futuros projetistas, foram sugeridas as bases essenciais relacionadas com seus critérios de projeto: separadores trifásicos, limites de velocidade ascensional $\left(\mathrm{V}_{\mathrm{a}}\right)$, tempo de detenção hidráulica (TDH), altura útil do reator, sistema de distribuição do afluente, retirada de lodo e de biogás etc.

É consenso que a proposição dos reatores UASB constituiu verdadeira revolução na área de tratamento de esgoto, pois quando seguidos de pós-tratamento adequado reduzem o custo de execução e de operação de estações de tratamento em cenários em que as características do esgoto e do clima se adequam aos pré-requisitos da tecnologia.

Os primeiros projetos foram concebidos com base na simplicidade original; porém, após os UASB serem colocados em operação, começaram a ser detectados problemas de concepção, execução, operação e manutenção. Evidentemente, a implantação de instalações adicionais para melhoria do desempenho resultou em maiores custos de implantação, operação e manutenção, principalmente no que se refere à remoção da escuma internamente aos separadores trifásicos (gás, líquido e sólido - GLS) e na superfície da região de decantação. Após cerca de quatro décadas de experiências práticas, tem-se tentado superar muitas limitações e problemas associados com a disposição, a construção e a manutenção dos elementos que constituem os componentes internos (distribuição do afluente e coleta do efluente líquido e de gases, dispositivos para a remoção de escuma etc.) (MIKI, 2010; VAN LIER. et al., 2010; HEFFERNAN et al., 2011).

A presente pesquisa versa sobre três tópicos que afetam os reatores UASB tradicionais: a eficiência dos separadores trifásicos na remoção de sólidos suspensos, o acúmulo de escuma na superfície líquida e a densidade de pontos de alimentação junto ao fundo.

Frequentemente, reatores UASB apresentam em seu efluente teor de sólidos sedimentáveis acima de $1 \mathrm{mLL}^{-1}$. Oliveira e Von Sperling (2011), baseados em levantamento de campo, observaram que $40 \%$ dos reatores analisados apresentavam sólidos suspensos totais (SST) acima de $100 \mathrm{mgL}^{-1} \mathrm{em}$ seu efluente. Por outro lado, à medida em que a expressiva retenção de escuma nos GLS e na região de decantação começou a suscitar problemas operacionais e de manutenção, começaram a surgir proposições sobre a sua remoção hidráulica (LETTINGA \& HULSHOFF POL, 1991).

Em recente publicação da Revista DAE (2018), em edição especial (v. 66, n. 214) são apresentadas notas técnicas - com amplo espectro - sobre projeto, operação e manutenção de reatores UASB. Entre essas notas, o trabalho do Lobato et al. (2018) enfoca a problemática relacionada com o acúmulo de escuma $\mathrm{e}$ afirma que esse fenômeno pode ser mitigado ou resolvido dispondo-se de um tratamento preliminar apropriado, assim como de projetos bem elaborados e, também, de operação e manutenção adequadas, auxiliados pelo uso de soluções alternativas, entre as quais a remoção hidráulica da escuma por receptáculos instalados nos GLS e na região de decantação.

Um questionamento óbvio seria o porquê de se utilizar agitação adicional na manta de lodo se os UASB convencionais apresentam bons resultados. Diante disso, serão aqui expostos alguns aspectos que levam à sugestão do presente artigo.

i) Originalmente os reatores UASB foram propostos como tratamento de baixo custo. Nesse contexto, não se tinha como objetivo um projeto otimizado hidrodinamicamente.

ii) Passig (2005), com base em sua pesquisa (e de outros autores citados por ele), comenta que foram detectados atrasos na recuperação do traçador (Eozina Y) e baixa recuperação desse traçador (74\%), caracterizando zonas mortas.

iii) Silva et al. (2015) relatam fenômenos que ocorrem em reatores UASB relacionados com períodos em que a vazão afluente é reduzida: formam-se bolsões gasosos retidos nas regiões mais profundas da manta de lodo. Quando a vazão retorna ao normal, esses bolsões desprendem-se e provocam grande concentração de sólidos (SST) no efluente.

iv) A mistura adicional pode potencialmente melhorar as condições hidrodinâmicas na manta, viabilizar a redução do número de pontos de alimentação e auxiliar no adensamento do lodo.

Na presente pesquisa, propõem-se:

i) o uso de manta de lodo anaeróbio, inserida num sistema baseado no conceito de lodo ativado: $\mathrm{o}$ anaerobic activated sludge blanket system ( $\mathrm{A}^{2} \mathrm{SBS}$ )

ii) a eliminação dos separadores trifásicos GLS de modo que a remoção dos SST do efluente da zona de reação passe a ser efetuada em decantadores lamelares;

iii) a redução do número de pontos de alimentação, fundamentada na agitação adicional na manta de lodo mediante mistura mecânica ou hidráulica com jatos.

Note-se que o $\mathrm{A}^{2} \mathrm{SBS}$, conceitualmente, é um sistema (que inclui reator biológico $-\mathrm{R}-$, decantador e recirculação de lodo) e, conceitualmente, o UASB é conhecido como um reator. Contudo, uma comparação em nível preliminar pode ser apresentada. 
Aspectos positivos do sistema $\mathrm{A}^{2} \mathrm{SBS}$ :

- a operação no conceito de lodo ativado permite o controle do tempo de retenção celular (TRC);

- os decantadores lamelares oferecem remoção de SST superior à dos GLS, o que resulta em aumento significativo do TRC;

- a agitação mecânica oferece maior flexibilidade operacional, decorrente da possibilidade de se controlar o gradiente de velocidade $\left(\mathrm{Gs}^{-1}\right)$ na manta; $\mathrm{e}$

- a introdução de mistura adicional pode permitir a redução do número de pontos de alimentação junto ao fundo do R e melhorar o adensamento do lodo.

Em contraposição, tem-se:

- aumento do custo de implantação. Esse custo é parcialmente compensado pela eliminação dos separadores GLS e do sistema instalado para a remoção de escuma;

- aumento do volume de lodo destinado ao desaguamento. Haverá aumento do volume, contudo ocorrerá diminuição da massa de sólidos. Como o TRC nos $\mathrm{A}^{2} \mathrm{SBS}$ é muito maior que o dos UASB, conceitualmente a degradação da matéria orgânica será, também, maior (embora a parcela de produtos inertes seja a mesma); e

- demanda de energia elétrica. O gradiente médio a ser aplicado será inferior a $20 \mathrm{~s}^{-1} \mathrm{e}$ intermitente. Isso resulta em motores de baixa potência para os misturadores. Por outro lado, as bombas para recirculação de lodo funcionam afogadas e com pequena altura manométrica.

\section{Conceitos das novas concepções}

Na Figura 1 são apresentados quatro esquemas conceituais referentes a reatores anaeróbios de manta de lodo. Na Figura 1A consta o conceito de reator UASB convencional, em que há separador trifásico e sistema de distribuição do esgoto junto ao fundo, com entradas individuais ( 1 a $4 \mathrm{~m}^{2}$ para cada ponto de alimentação). Segundo a norma brasileira NBR 12.209 (ABNT, 2011), a velocidade ascensional $\left(\mathrm{V}_{\mathrm{a}}\right)$ média nesse tipo de reator, na região de reação, deve ser inferior a $0,7 \mathrm{mh}^{-1}$ para a vazão média - limite geralmente usado por projetistas. Nas concepções das Figuras 1B, 1C e 1D são apresentadas ilustrações conceituais propostas neste artigo, em que são completamente eliminados os separadores trifásicos (e o sistema para a remoção de escuma) e é simplificado o sistema de alimentação. Em ambos os casos, introduz-se a sedimentação de alta taxa para a remoção dos sólidos suspensos do efluente da região de reação.

Na Figura 1B a manta de lodo é mantida mediante agitação mecânica intermitente $\left(\mathrm{A}^{2} \mathrm{SBS}_{\mathrm{m}}\right.$ ), e na Figura $1 \mathrm{C}$ a mistura é obtida com jatos de bocais $\left(\mathrm{A}^{2} \mathrm{SBS}_{\mathrm{j}}\right)$, também intermitentes. Ambos os casos permitem a redução do número de entradas. Ao se promover a agitação mecânica ou a mistura por jatos de bocais, uma única entrada pode substituir vários pontos individuais quando definidos de acordo com os conceitos tradicionais. No que se refere à nova concepção expressa na Figura $1 \mathrm{C}$, é importante destacar que os bocais devem ser alimentados intermitentemente para se conseguir alta velocidade de saída, com jatos de longo alcance. Isso não é possível se a vazão nesses acessórios for igual à vazão afluente do esgoto bruto. Diante disso, na(s) linha(s) de alimentação do(s) bocal/is), há necessidade de se ter um tanque-pulmão (tempo médio de detenção de apenas alguns poucos minutos) em cuja(s) canalização/ões de saída seja(m) instalada(s) válvula(s) para abertura e fechamento automáticos, controlada(s) por medidor de nível instalado no tanque-pulmão.

A Figura 1D mostra um sistema cujo R respeita o sistema tradicional, porém sem GLS e sem sistema para a remoção de escuma.

Na Figura 2 são apresentados esquemas simplificados dos componentes do R, em diferentes configurações.

Uma outra diferença essencial entre a concepção convencional do UASB e a desta proposta recai no fato de que parcela de lodo retido no sedimentador é recirculada $\left(\mathrm{Q}_{\mathrm{R}}\right)$ para o $\mathrm{R}$ propriamente dito. Além disso, na mesma linha há alternativa para o descarte do lodo em excesso a ser enviado ao desaguamento. Esse recurso, além de facilitar a manutenção da manta de lodo, permite o controle da idade do lodo no sistema, dando flexibilidade operacional para se alcançar o melhor desempenho do processo.

Na realidade, as proposições deste artigo permitem que o conjunto seja operado como um sistema de lodo ativado anaeróbio de manta de lodo. Trata-se de uma proposta original, pois ela se diferencia da concepção mais próxima, que seria o tratamento anaeróbio por contato em que se adota mistura completa. Segundo Metcalf e Eddy (2016), os sistemas de lodo ativado por contato têm as seguintes características principais: TRC de 15 a 30 dias, sólidos suspensos voláteis (SSV) no reator de 4000 a $8000 \mathrm{mgL}^{-1}$, tempo de detenção hidráulica da ordem de dia ou dias e mistura completa. Portanto, o A² $\mathrm{SBS}$ é uma concepção completamente diferente.

No contexto do $\mathrm{A}^{2} \mathrm{SBS}$, com mistura adicional ou com sistema de distribuição convencional, sem agitação, recomendam-se:

- a implantação de tratamento preliminar de elevada eficiência - para estações de grande porte, sugere-se que o desarenador seja também adequado para remover sólidos flutuantes (recomendação válida, também, para reatores UASB). O resíduo flutuante pode ser degradado em reator anaeróbio específico e retornado ao fluxograma da estação de tratamento de esgoto (ETE) (BORGES, 2014);

- a coleta do efluente do R em canaletas (sem anteparos) com vertedores (sessão retangular, semicircular ou trapezoidal, lâmina mínima de $3 \mathrm{~cm}$ e descarga livre). Vertedores triangulares são mais susceptíveis à retenção de fragmentos consolidados de material flutuante. O uso de canalizações (fixas na laje do reator) perfuradas com jatos direcionais (opcionais), distribuídas ao longo de seu comprimento (com água de serviço), pode auxiliar no arraste da escuma em direção aos vertedores;

- a coleta do efluente dos decantadores lamelares com tubos perfurados (ou calhas com anteparos) para facilitar a remoção de sólidos flutuantes por dispositivos adequados. A escuma que se acumularia na superfície do $\mathrm{R}$ será transferida para o decantador. Sua remoção, nesse caso, é simplificada, pois a área do decantador será da ordem de $20 \%$ da área do reator (seguindo os resultados desta pesquisa). Em ETE de pequeno porte, podem-se usar fundos troncocônicos, porém em ETE de grande porte há necessidade de raspador de fundo;

- a programação da recirculação do lodo sedimentado para que haja condição de ocorrer adensamento desse lodo. As bombas deverão ser afogadas para reduzir a altura manométrica do recalque. Os decantadores deverão ter recursos para possibilitar a interrupção do afluente e para descarga em nível acima da região de acúmulo de lodo durante operação de limpeza além da descarga de fundo, evidentemente. 
A) SISTEMA UASB - CONCEPÇĀO CONVENCIONAL (1 a $4 \mathrm{~m}^{2}$ POR UNIDADE DE ALIMENTAÇÃO NO RUNDO)

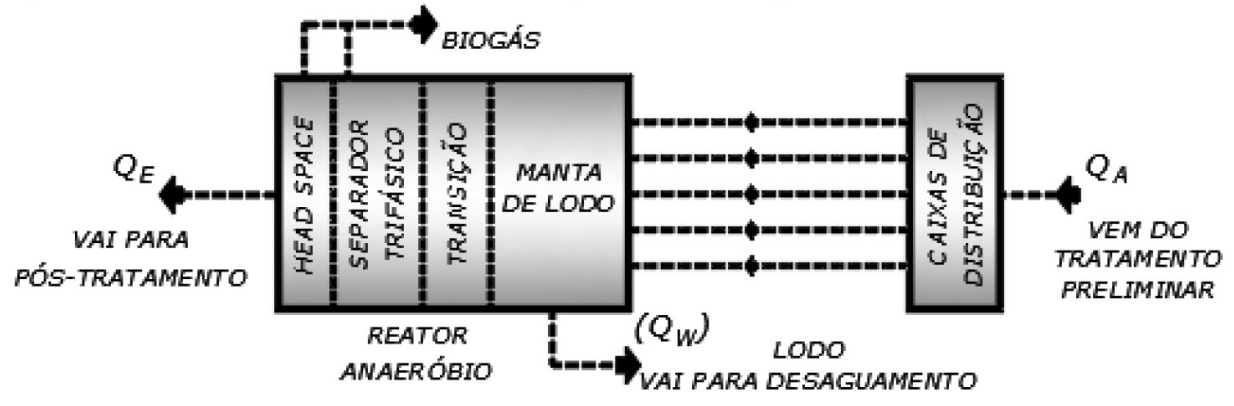

B) $A^{2} S_{m}$ COM MISTURA MECÂNICA INTERMTTENTE

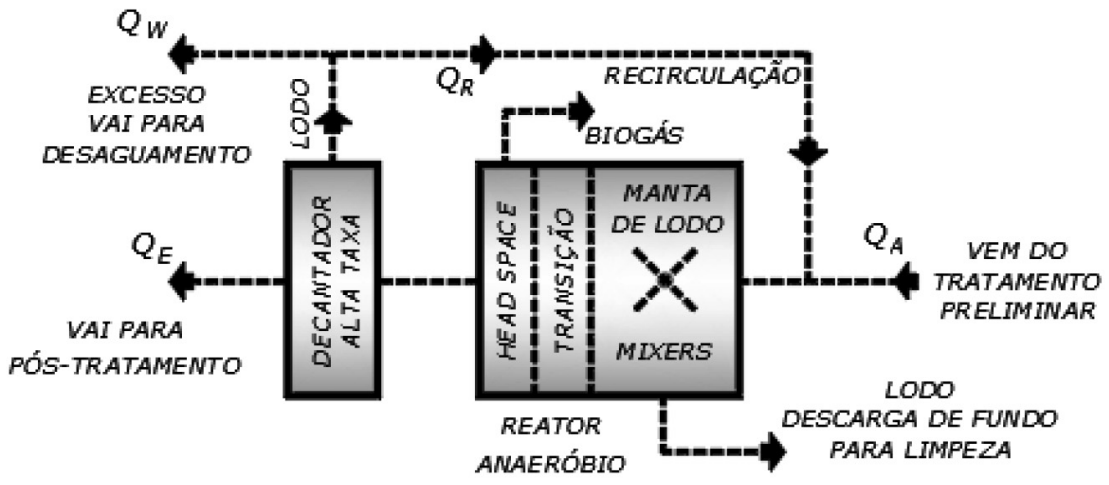

C) A $^{2}$ SBS $_{j}$ COM MISTURA POR JATOS INTERMTIENTES (BOCAIS)

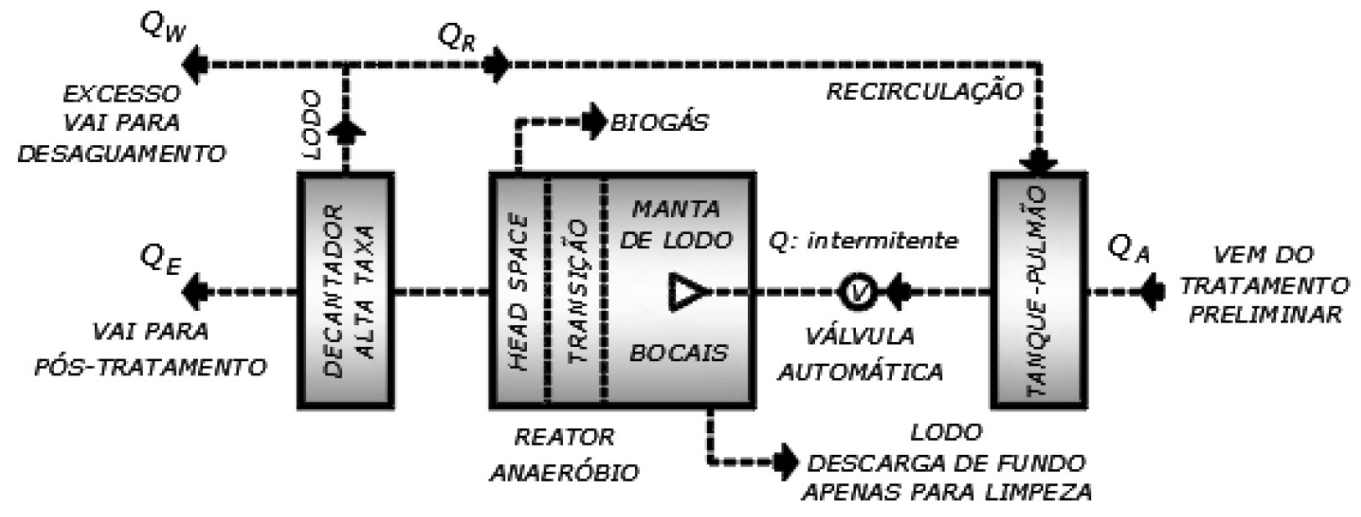

D) A A $^{2}$ SBS SEM MISTURA ADICIONAL

( 1 a $4 \mathrm{~m}^{2}$ POR UNIDADE DE AL IMENTAÇ̃̃o NO FUNDO)

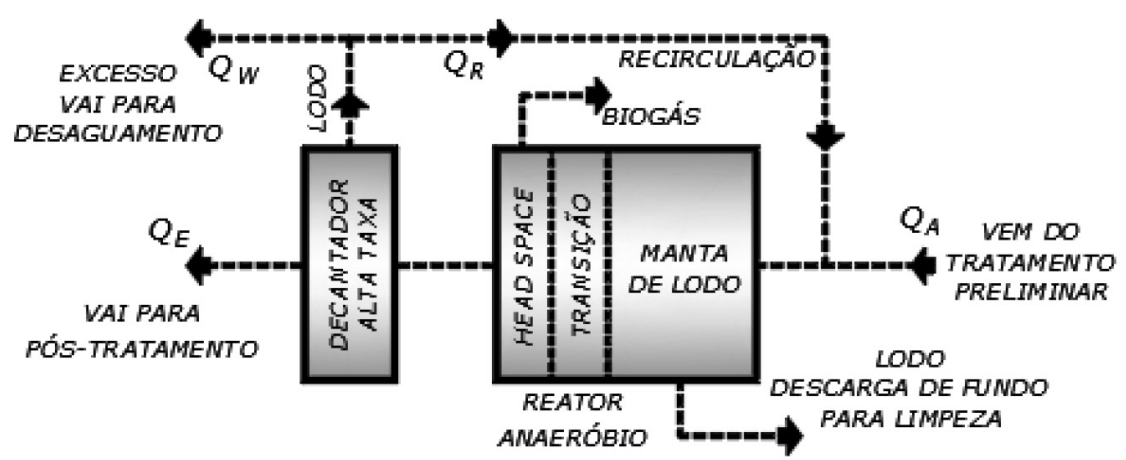

UASB: upflow anaerobic sludge blanket reactors; A²SBS: activated anaerobic sludge blanket system. Fonte: elaborada pelos autores

Figura 1 - Conceitos do reator upflow anaerobic sludge blanket tradicional e das novas propostas para sistema anaeróbio de lodo ativado com manta de lodo. 
UASB CONVECIONAL

TAMPA
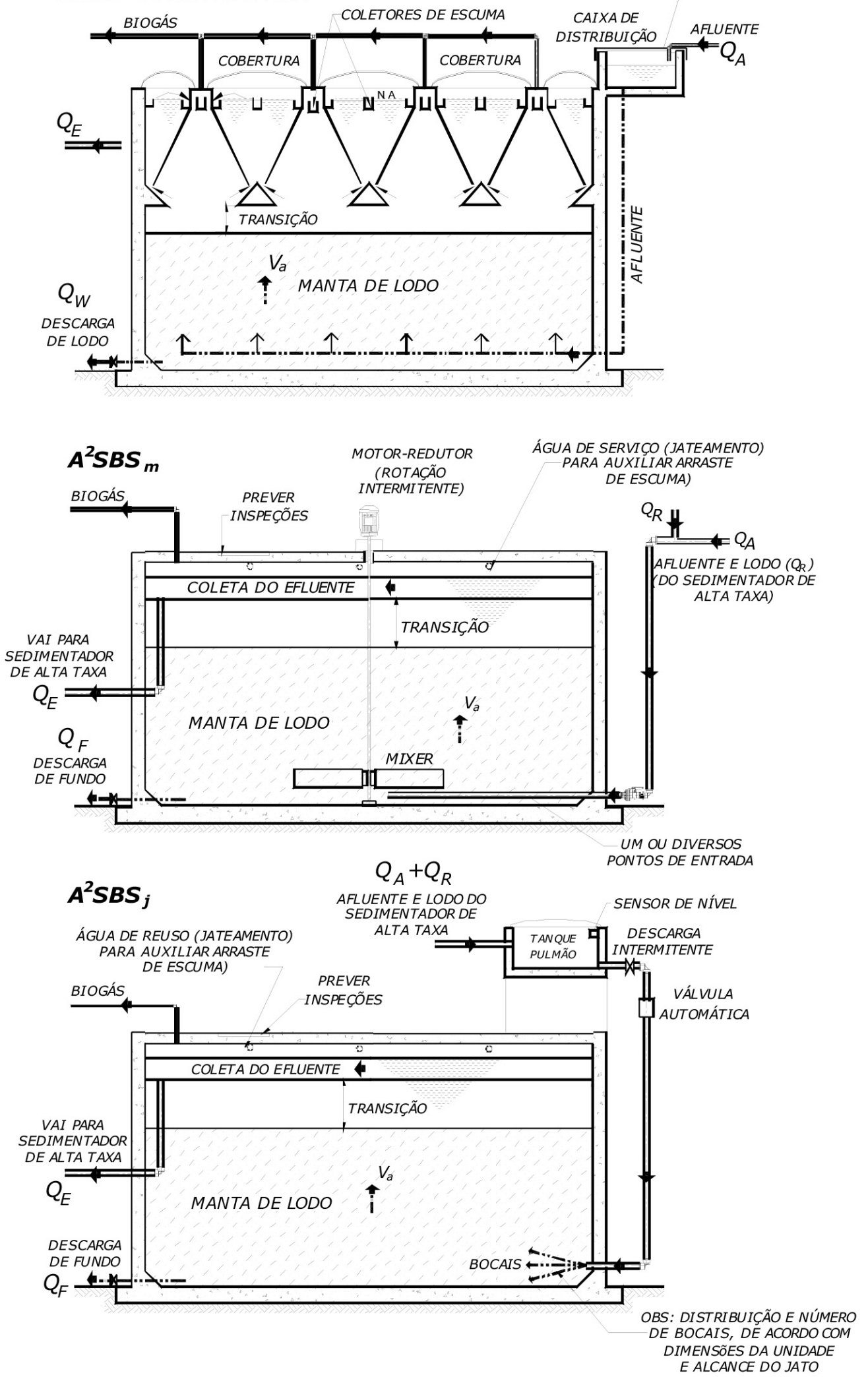

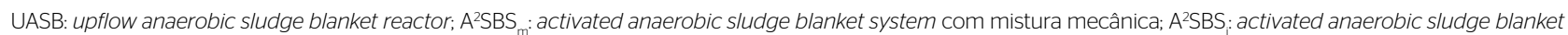
system por jatos intermitentes. Fonte: elaborada pelos autores.

Figura 2 - Comparação de concepções de reatores anaeróbios de manta de lodo: reator upflow anaerobic s/udge blanket concepção original e activated anaerobic sludge blanket system com mistura mecânica ou por jatos intermitentes. 


\section{METODOLOGIA}

\section{Testes e resultados preliminares}

Neste item, apresentar-se-á um resumo das principais conclusões dos ensaios e testes que precederam ao projeto e à operação das instalações-piloto. Foram realizados testes para estudar parâmetros relacionados com a agitação (gradiente de velocidade) para a mistura adequada e para a suspensão de material acumulado no fundo.

Foram operados, posteriormente, três reatores de bancada em aparelho convencional tipo jar-test (volume de cada reator: $2 \mathrm{~L}$ ), devidamente inoculados, alimentados com esgoto sanitário e mantidos em temperatura de $(22 \pm 2)^{\circ} \mathrm{C}$. Variaram-se o TDH médio e o gradiente de velocidade $(\mathrm{G})$ da seguinte forma: i) Reator 1: sem agitação G $=0 \mathrm{~s}^{-1}$ e TDH: $8 \mathrm{~h}$; ii) Reator 2: $\mathrm{G}=20 \mathrm{~s}^{-1}$ e TDH: $8 \mathrm{~h}$; iii) Reator 3: $\mathrm{G}=20 \mathrm{~s}^{-1} \mathrm{e}$ TDH: $4 \mathrm{~h}$. Os reatores foram monitorados para avaliar seu desempenho na remoção de demanda química de oxigênio (DQO).

Os resultados foram, de certa forma, surpreendentes e permitiram concluir que:

i) é necessário que se criem condições para se estruturar a manta de lodo; a mistura completa é prejudicial;

ii) é necessário ter-se gradiente médio de velocidade menor que $20 \mathrm{~s}^{-1}-$ apenas o suficiente para manutenção da manta;

iii) para se promover a suspensão total do material acumulado no fundo, é necessário $\mathrm{G} \geq 80 \mathrm{~s}^{-1}$. Esse valor elevado de $\mathrm{G}$ não foi o usado na operação de rotina, foi apenas uma constatação.

Com relação ao valor do gradiente de velocidade adicional médio menor que $20 \mathrm{~s}^{-1}$, pode-se considerar que se tratou de uma conclusão bastante favorável para o prosseguimento da pesquisa, pois isso resulta no baixo consumo de energia a ser aplicada nos reatores mediante a mistura mecânica.

Para a pesquisa destinada à mistura com jatos, houve necessidade de se concretizarem passos relacionados com a escolha do tipo de bocal e a realização de testes hidráulicos (perda de carga, alcance do jato etc.). Após estudo da bibliografia (LENCASTRE, 1957; AZEVEDO NETTO, 1998; HARNBY et al., 2001), optou-se pelo bocal com a configuração apresentada na Figura 3: baixa perda de carga localizada e elevada dissipação de energia, com o intuito de minimizar problemas de entupimentos e melhorar o efeito da mistura.

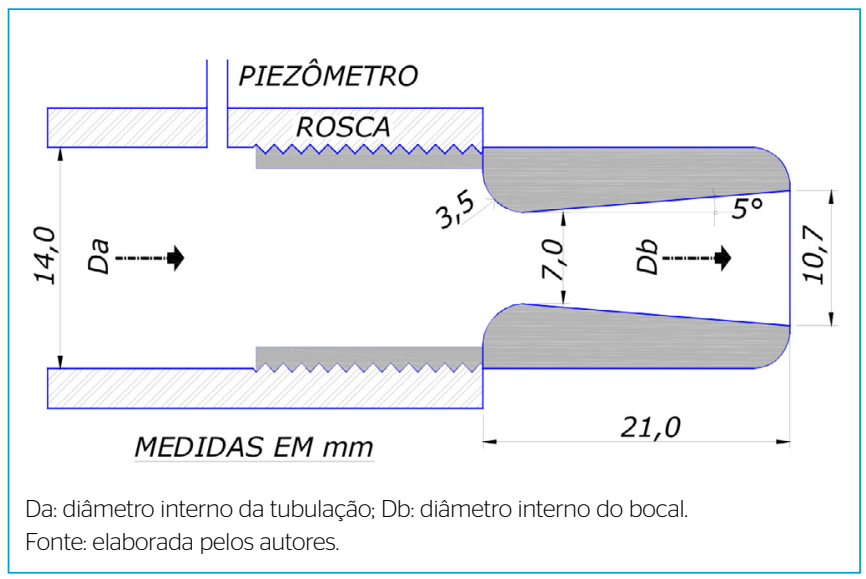

Figura 3 - Tipo de bocal empregado na pesquisa.
Empregando-se um tanque construído em acrílico (1,75 m x 1,75 m x $0,88 \mathrm{~m}$ ) e sistemas de câmeras fotográficas sincronizadas, foram feitos testes com bocais (aço inox) com diâmetro da seção contraída $\left(D_{\mathrm{b}}\right)$ de $7,0 \mathrm{~mm}$. Também foram efetuados testes hidrodinâmicos com os traçadores cloreto de sódio e rodamina B (LEVENSPIEL, 2000). Antecedendo à unidade, foi construído tanque-pulmão com volume de $36 \mathrm{~L}\left(1,3 \%\right.$ do volume do reator: $\left.2,7 \mathrm{~m}^{3}\right)$, com descargas intermitentes.

Concluiu-se que a concepção adotada tinha excelentes condições para a mistura. Nessa concepção não se utilizaram separadores GLS nem sedimentação de alta taxa.

Baseando-se nessas constatações, foram projetadas duas instalações-piloto em paralelo (com sedimentador de alta taxa) para testes com agitação mecânica e com jatos.

Essa etapa inicial da pesquisa (aqui resumida) estendeu-se por período de cerca de dois anos.

\section{Instalações-piloto}

Foram projetados e construídos dois sistemas experimentais para os testes das alternativas com mistura mecânica $\left(\mathrm{A}^{2} \mathrm{SBS} \mathrm{m}_{\mathrm{m}}\right)$ e com jatos $\left(\mathrm{A}^{2} \mathrm{SBS} \mathrm{S}_{\mathrm{j}}\right)$.

$O$ volume total de cada sistema completo (Reator- $\mathrm{R}+$ Sedimentador-S) era de 20,8 $\mathrm{m}^{3}$ (2,0 $\left.\mathrm{m} \times 2,0 \mathrm{~m} \times 5,2 \mathrm{~m}\right)$, e o volume do R ocupava 17,0 $\mathrm{m}^{3}$ (Figura 4)

O setor de reação é seguido por componente para a remoção de sólidos suspensos, constituído de sedimentador de alta taxa com placas planas paralelas. $\mathrm{O}$ sedimentador tinha fundo com paredes inclinadas para possibilitar o armazenamento e o adensamento do lodo e um conjunto elevatório externo para promover a sua recirculação $\left(Q_{R}\right)$ até a entrada do respectivo $R$. Na canalização de recalque há derivações para viabilizar o descarte do lodo em excesso $\left(Q_{W}\right)$ e coleta de amostras.

Embora não tenham sido encontrados dados sobre projetos de sedimentadores de alta taxa para efluentes de reatores anaeróbios, foram usados conceitos básicos sobre o tema, aplicados ao tratamento de água em Hazen e Culp (1967), Yao (1970, 1972, 1973) e Richter (2009).

Assim, este trabalho baseou-se nas seguintes premissas:

i) o espaçamento entre as placas deve ser de $4 \mathrm{~cm}$;

ii) normalmente se usa inclinação das placas de $60^{\circ}$ para água de abastecimento; adotou-se $70^{\circ}$ para melhorar o movimento descendente dos sólidos retidos;

iii) embora se usem valores mais elevados de taxa de aplicação superficial (TAS) em sedimentadores de alta taxa para tratamento de água, adotou-se como limite a ser pesquisado a taxa de $81,6 \mathrm{~m}^{3} \mathrm{~m}^{-2} \mathrm{dia}^{-1}$, por medida de segurança.

O comprimento a ser percorrido pelo líquido entre as placas foi fixado em $1,0 \mathrm{~m}$, e a área efetivamente coberta pelos módulos (placas inclinadas) foi de $0,816 \mathrm{~m}^{2}$ (20,4\% da área superficial do R).

No sistema $\mathrm{A}^{2} \mathrm{SBS}_{\mathrm{m}}$ foi instalado conjunto adequado para promover a aplicação de gradiente de velocidade variável de $0 \mathrm{a} 80 \mathrm{~s}^{-1}$, com base em seu dimensionamento conforme expresso na Equação 1 - geralmente aceita para o dimensionamento de sistemas com agitação (CLEASBY, 1984; BRIDGEMAN, 2012).

$G=\sqrt{\frac{P}{\mu V}}$

Em que: P: potência aplicada no líquido $\left(\mathrm{Nms}^{-1}\right) ; \mu$ : viscosidade dinâmica do fluido $\left(\mathrm{Nsm}^{-2}\right)$; V: volume da unidade $\left(\mathrm{m}^{3}\right)$; G: gradiente médio de velocidade $\left(\mathrm{s}^{-1}\right)$ 


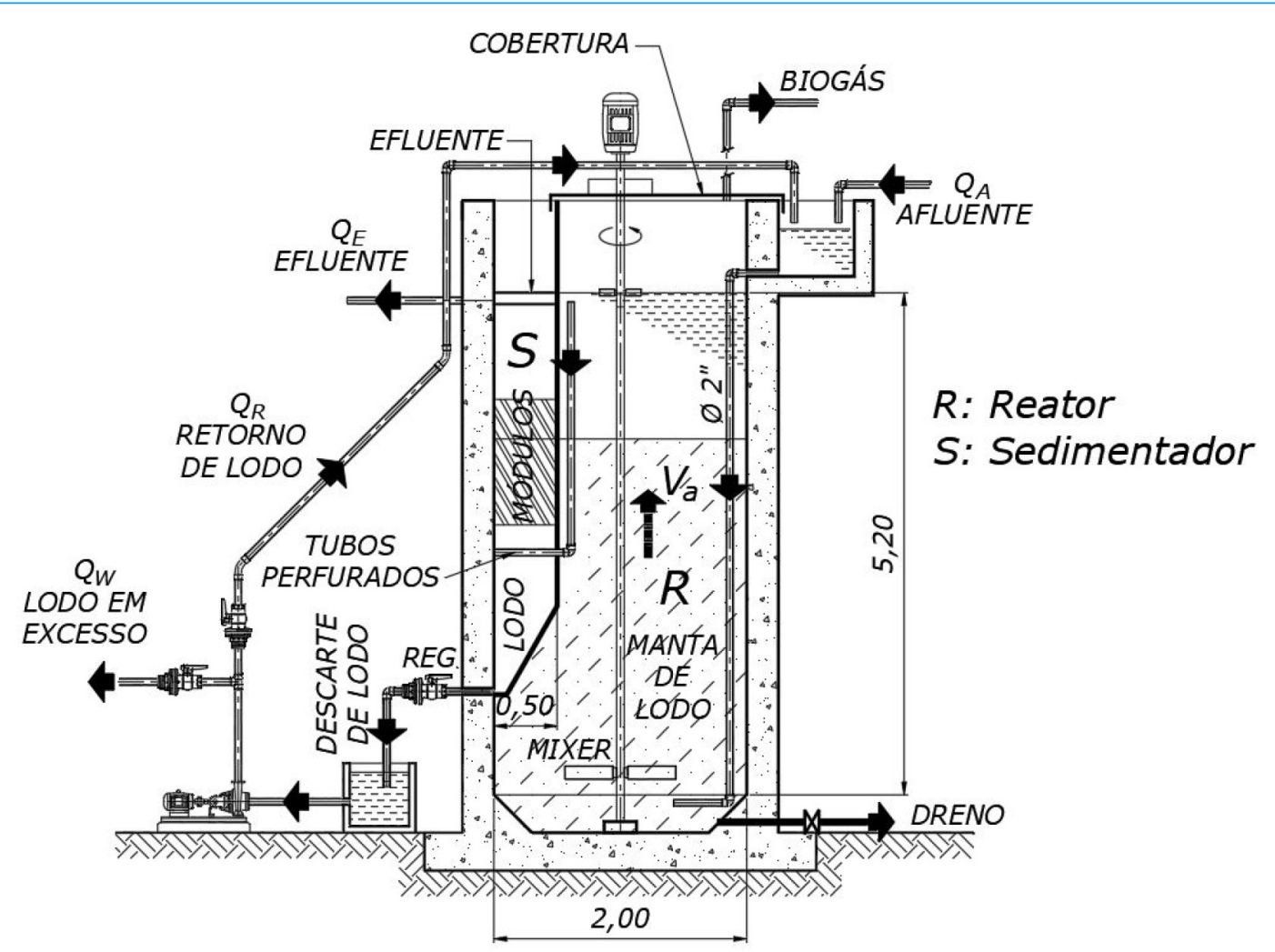

$V_{a}$ : velocidade ascensional; $R$ : reator biológico. Fonte: elaborada pelos autores.

Figura 4 - Instalação piloto: mistura mecânica.

O dimensionamento do equipamento de agitação seguiu preceitos apregoados por Atiemo-Obeng et al. (2003) e Leng et al. (2008), adotando-se: $\mu=1,113 \times 10^{-3} \mathrm{Nsm}^{-2}$, massa específica $(\rho)$ de $1,108 \mathrm{kgL}^{-1}$ e teor de sólidos em suspensão de até $11 \%$. Nesse cenário, chegou-se a um agitador axial com diâmetro com cerca de 1/3 do lado dos reatores (quadrados, em planta).

Empregando-se a Equação 1, chegou-se à demanda de potência efetivamente dissipada de cerca de $2 \mathrm{~W}$ para $\mathrm{G}=10 \mathrm{~s}^{-1}\left(0,118 \mathrm{Wm}^{-3}\right)$, de $7,5 \mathrm{~W}$ para $\mathrm{G}=20 \mathrm{~s}^{-1}\left(0,45 \mathrm{Wm}^{-3}\right)$ e de $121 \mathrm{~W}$ para $\mathrm{G}=80 \mathrm{~s}^{-1}\left(7,12 \mathrm{Wm}^{-3}\right)$. A rotação (teórica) do agitador resultou em 16,0 rpm (para G $=10 \mathrm{~s}^{-1}$ ), 17,8 rpm (para G $=20 \mathrm{~s}^{-1}$ ) e 63,0 rpm (para $\left.\mathrm{G}=80 \mathrm{~s}^{-1}\right)$.

Após muitos testes preliminares de campo (tentativa e erro), durante a pesquisa propriamente dita se empregou $\mathrm{G}$ médio $2,5 \mathrm{~s}^{-1}$, porém sempre inferior a $10 \mathrm{~s}^{-1}$, com acionamento intermitente ( $3 \mathrm{~min}$ : ligado; $17 \mathrm{~min}$ : desligado).

Não se encontram trabalhos significativos sobre a mistura mecânica em reatores de manta de lodo, mas somente em sistemas anaeróbios de contato e digestores de lodo. Nesse cenário prevalecem opiniões de que a mistura intermitente é a mais adequada e que a alta densidade de potência $\left(\mathrm{Wm}^{-3}\right)$ deve ser evitada (KARIYAMA et al., 2018).

Lembre-se que, em testes de bancada, chegou-se à conclusão de que o gradiente G deveria ser inferior a $20 \mathrm{~s}^{-1}$. Na instalação piloto, o G necessário foi ainda menor.

Por segurança, para se especificar o motor da instalação piloto, adotou-se a densidade de potência de $1,8 \mathrm{~W}\left(1.000 \mathrm{~m}^{3}\right)^{-1}$, com operação intermitente. Assim, houve superdimensionamento do motor, porém a energia efetivamente aplicada foi apenas dependente da rotação empregada e correspondente a $\mathrm{G}=2,5 \mathrm{~s}^{-1}$.
No caso do sistema $\mathrm{A}^{2} \mathrm{SBR}$, baseando-se nos resultados das etapas anteriores, instalou-se bocal com $\mathrm{D}_{\mathrm{b}}$ de $42 \mathrm{~mm}$, cujo coeficiente de descarga (Cd), determinado na pesquisa, resultou em 0,82 . O volume útil do tanque-pulmão foi fixado em $152 \mathrm{~L}$, correspondendo a $0,89 \%$ do volume total do R. O desnível entre o nível mínimo e máximo no tanque-pulmão resultou em 1,66 m e 1,80 m em relação ao nível da água no $\mathrm{R}$.

A operação de alimentação é cíclica e automática:

i) a válvula de saída do tanque-pulmão é fechada após a descarga dos jatos;

ii) há o enchimento do tanque-pulmão com o esgoto afluente (tempo de duração: Ta);

iii) ocorre a abertura da válvula após o enchimento e a descarga do tanque-pulmão até seu esvaziamento (duração do esvaziamento - Te).

O tempo de descarga foi aproximadamente constante (30 s) e o do enchimento, variável (de 3,0 a 6,5 min.).

As estimativas da vazão de descarga do tanque-pulmão e do gradiente de velocidade aplicado foram baseadas nas Equações 2 a 4 (AZEVEDO NETTO et al., 1998):

$\mathrm{Q}=\mathrm{Cd} \cdot \mathrm{A}_{\mathrm{b}} \sqrt{2 \cdot \mathrm{g} \cdot \mathrm{h}_{\mathrm{P}}}$

Pot: $\gamma \cdot Q \cdot h_{d}$

$\mathrm{G}=\sqrt{\frac{\gamma \mathrm{Qh}_{\mathrm{d}}}{\mu \mathrm{V}}}$ 
Em que: Pot: potência (W) efetivamente dissipada no meio; G: gradiente de velocidade $\left(\mathrm{s}^{-1}\right)$; $\mathrm{Q}$ : vazão $\left(\mathrm{m}^{3} \mathrm{~s}^{-1}\right)$; Cd: coeficiente de descarga; $\mathrm{A}_{\mathrm{b}}$ : área da sessão contraída no bocal $\left(\mathrm{m}^{2}\right)$; g: aceleração da gravidade $\left(\mathrm{ms}^{-2}\right)$; $\mathrm{h}$ : carga manométrica aplicada na entrada do bocal (mca); $\Upsilon$ : peso específico $\left(\mathrm{Nm}^{-3}\right)$; $\mu$ : viscosidade dinâmica $\left(\mathrm{Nsm}^{-2}\right)$; $\mathrm{V}$ : volume $\left(\mathrm{m}^{3}\right)$; $\mathrm{h}_{\mathrm{d}}$ : carga (mca) efetivamente dissipada no meio, descontando perda no bocal. Também foram levadas em consideração as Equações 5 e 6 (HARNBY et al., 2001), referentes ao alcance dos jatos.

$\mathrm{Z}=\frac{\mathrm{V}_{\mathrm{j}} \cdot \mathrm{D}_{\mathrm{c}} \cdot 6}{\mathrm{~V}_{\mathrm{Z}}}$

$\mathrm{A}_{\ell}=\frac{\mathrm{Z}}{6}$

Em que: $\mathrm{Z}$ : alcance máximo do jato referente à velocidade $\mathrm{V}_{\mathrm{Z}}(\mathrm{m}) ; \mathrm{V}_{\mathrm{j}}$ : velocidade média do jato na saída do bocal $\left(\mathrm{ms}^{-1}\right) ; \mathrm{D}_{\mathrm{C}}$ : diâmetro na saída do bocal $(\mathrm{m}) ; \mathrm{V}_{\mathrm{Z}}$ : velocidade mínima requerida na distância $\mathrm{Z}\left(\mathrm{m}, \mathrm{s}^{-1}\right) ; \mathrm{A}_{\mathrm{L}}$ : alcance lateral do jato (m) na distância Z (m).

\section{Operação}

Durante o período experimental, a instalação foi alimentada com esgoto sanitário após passar por desarenador e peneira com aberturas de $3 \mathrm{~mm}$. O sistema foi operado exposto ao meio ambiente e, assim, passível de sofrer interferências de variações nas características da temperatura do esgoto. Durante a pesquisa a temperatura média diária resultou na faixa de $24 \pm 3{ }^{\circ} \mathrm{C}$. As características médias do esgoto bruto, antes do tratamento preliminar, estão apresentadas na Tabela 1.

Nesta pesquisa, as eficiências dos $\mathrm{A}^{2} \mathrm{SBS}$ estão relacionadas com o efluente do tratamento preliminar (e não com o esgoto bruto: Tabela 1), que, por sua vez, apresentou eficiência acima do usual. A remoção de DQO e de SST, nesta etapa, resultou da ordem de 40 e $25 \%$, respectivamente, de modo que o esgoto poderia ser classificado como de concentração média segundo Metcalf e Eddy (2016).

Antecedendo ao levantamento de dados experimentais, os reatores foram inoculados e monitorados até ser atingido o equilíbrio dinâmico aparente, após fase de testes e ajustes iniciais. Nesse período foi utilizado inóculo em diferentes ocasiões, constituído de lodo proveniente dos reatores UASB da ETE Monjolinho (São Carlos/SP: $\mathrm{Q}_{\mathrm{MED}}=600 \mathrm{Ls}^{-1}$ ), com as seguintes características médias: $\mathrm{SST}$ : $31.072 \mathrm{mgL}^{-1}$; sólidos suspensos voláteis (SSV): $19.976 \mathrm{mgL}^{-1}$, sólidos suspensos fixos (SSF): $11.096 \mathrm{mgL}^{-1} \mathrm{e}$ atividade metanogênica específica (AME): 0,034 $\operatorname{kg}$ DQO $_{\text {REM }} \cdot(k g S S V . d)^{-1}$.

Precedendo à operação de rotina dos sistemas, foram realizados vários testes no conceito tentativa e erro com base nos resultados prévios de laboratório e de reator em pequena escala. Esse período abrangeu cerca de cinco meses no caso do $\mathrm{A}^{2} \mathrm{SBS}_{\mathrm{m}}$ e período mais longo para o $\mathrm{A}^{2} \mathrm{SBS}$.

Confirmou-se que valores elevados de $\mathrm{G}$ eram prejudiciais à eficiência do sistema e que era necessária apenas uma agitação mínima para que se pudesse manter estável a manta de lodo; isso porque, com a elevação de G, a eficiência decaía consideravelmente. Nessas tentativas, evidentemente, em algumas ocasiões houve arraste de sólidos no efluente, o que exigiu novas inoculações. Concluiu-se também que a agitação intermitente oferecia melhores resultados que a agitação contínua.
Tabela 1- Características médias principais do esgoto afluente ao tratamento preliminar.

\begin{tabular}{l|c|c|c|c} 
Parâmetro & Unidade & Mínimo & Média & Máximo \\
\hline DBO & $\mathrm{mgL}^{-1}$ & 130 & 306 & 331 \\
\hline DQO filtrada & $\mathrm{mgL}^{-1}$ & 246 & 255 & 257 \\
\hline DQO bruta & $\mathrm{mgL}^{-1}$ & 522 & 570 & 580 \\
\hline Sulfeto & $\mathrm{mgS}^{-1} \mathrm{~L}^{-1}$ & & 0,06 & 12 \\
\hline ST & $\mathrm{mgL}^{-1}$ & & 608 & \\
\hline STV & $\mathrm{mgL}^{-1}$ & & 400 & \\
\hline STF & $\mathrm{mgL}^{-1}$ & & 280 & \\
\hline SST & $\mathrm{mgL}^{-1}$ & & 209 & \\
\hline SSF & $\mathrm{mgL}^{-1}$ & & 186 & \\
\hline SSV & $\mathrm{mgL}^{-1}$ & & & \\
\hline
\end{tabular}

DBO: demanda bioquímica de oxigênio; DQO: demanda química de oxigênio; ST: sólidos totais; STV: sólidos totais voláteis; STF: sólidos totais fixos; SST: sólidos suspensos totais; SSF: sólidos suspensos fixos; SSV: sólidos suspensos voláteis. Fonte: elaborada pelos autores.

As condições de mistura e de gradientes de velocidade já foram explicitadas anteriormente no texto deste artigo. $\mathrm{O}$ sistema $\mathrm{A}^{2} \mathrm{SBRS}_{\mathrm{m}}$ foi operado considerando-se quatro fases com diferentes tempos de retenção hidráulica $(\mathrm{TRH})$ no reator anaeróbio (R): 14,7, 11,0, 8,2 e 6,1 horas. No sistema $\mathrm{A}^{2} \mathrm{SBS}_{\mathrm{j}}$, ocorreram vários incidentes que prejudicaram a obtenção de número e qualidade de análises durante parte do monitoramento. Foram impostos os tempos de detenção hidráulica de 12,3, 9,8, 8,2 e 6,5 horas no R; contudo, neste artigo, será considerado apenas o TDH de 9,8 horas, pois nesse caso o período de operação (79 dias) e o número de campanhas foi adequado, oferecendo maior confiabilidade. Para esse cenário, foram impostas as condições:

i) $\mathrm{TDH}: 9,8$ horas;

ii) velocidade do esgoto na saída do bocal: $1,55 \mathrm{~ms}^{-1}$;

iii) velocidade com a qual o jato alcançava a parede oposta: $0,35 \mathrm{~ms}^{-1}$;

iv) perda de carga no sistema hidráulico de alimentação do bocal: 0,98 mca;

v) tempo médio de cada descarga: $30 \mathrm{~s}$;

vi) tempo médio de enchimento do tanque-pulmão (5,3 min); vii) gradiente de velocidade durante cada descarga: $16,6 \mathrm{~s}^{-1}$;

vii) vazão média durante a descarga: $5 \mathrm{Ls}^{-1}$.

Durante a pesquisa, a SST totais no lodo sedimentado (decantador) e recirculado no sistema variou na faixa de 1,5 a $3,8 \%$, e a relação $Q_{R} / Q_{A}$ variou entre 2,1 e 5,0\% no sistema $\mathrm{A}^{2} \mathrm{SBS}$. No sistema $\mathrm{A}^{2} \mathrm{SBRS}$ a relação entre $\mathrm{Q}_{R} \mathrm{e}$ $\mathrm{Q}$ resultou próximo a $1,5 \%$.

As condições operacionais básicas que foram respeitadas para os sistemas são caracterizadas na Tabela 2 .

Em cada fase foram realizadas campanhas de coletas (amostras compostas, durante 24 horas) e análises de acordo com protocolos de APHA (2012). Além de se efetuarem análises do afluente e do efluente dos reatores e dos decantadores, foi monitorada a manta de lodo e as características do lodo recirculado.

Por ser a manta de lodo um ponto fundamental nesta pesquisa, ela foi monitorada durante todo o período experimental, com amostras retiradas ao longo da altura dos reatores (com mistura mecânica junto ao fundo e a 1,5, 3,0 e 4,5 m; e com mistura por jatos junto ao fundo e a 2,0 3,4 e 4,2 m). Para DQO foram analisadas amostras e filtradas e, para sólidos suspensos, SSV e SST. 
Tabela 2 - Condições operacionais dos sistemas após os procedimentos de ajustes e de partida.

\begin{tabular}{|c|c|c|c|c|c|c|c|c|c|}
\hline \multicolumn{5}{|c|}{$\mathrm{A}^{2} \mathrm{SBR}_{\mathrm{m}}$ mistura mecânica } & \multicolumn{5}{|c|}{$\mathrm{A}^{2} \mathrm{SBR}_{\mathrm{j}}$ mistura por jatos } \\
\hline Fase & $\begin{array}{l}\text { Duração } \\
\text { (dia) }\end{array}$ & $\begin{array}{l}\text { TDH no } \\
\text { reator (h) }\end{array}$ & $\begin{array}{c}\mathrm{V}_{\mathrm{a}} \text { no reator } \\
\left(\mathrm{mh}^{-1}\right)\end{array}$ & $\begin{array}{c}\text { TAS no } \\
\text { decantador } \\
\left(\mathrm{m}^{3} \mathrm{~m}^{-2} \mathrm{dia}^{-1}\right)\end{array}$ & Fase & $\begin{array}{l}\text { Duração } \\
\text { (dia) }\end{array}$ & $\begin{array}{l}\text { TDH no } \\
\text { reator (h) }\end{array}$ & $\begin{array}{c}\mathrm{V}_{\mathrm{a}} \text { no reator } \\
\left(\mathrm{mh}^{-1}\right)\end{array}$ & $\begin{array}{c}\text { TAS no } \\
\text { decantador } \\
\left(\mathrm{m}^{3} \mathrm{~m}^{-2} \mathrm{dia}^{-1}\right)\end{array}$ \\
\hline 1 & 43 & 14,7 & 0,39 & 34,0 & \multirow{3}{*}{ I } & \multirow{3}{*}{\multicolumn{4}{|c|}{$\begin{array}{l}\text { Esta fase estendeu-se por seis meses, com testes (tentativa e erro) } \\
\text { de TDH de 12,26, 8,17 e 6,54 horas no reator biológico. Também } \\
\text { foram feitos testes com e sem recirculação do lodo. Como não foi } \\
\text { possível alcançar equilíbrio dinâmico nesse período experimental, } \\
\text { esses resultados são omitidos neste artigo. }\end{array}$}} \\
\hline ॥ & 29 & 11,0 & 0,52 & 45,6 & & & & & \\
\hline III & 14 & 8,2 & 0,69 & 61,2 & & & & & \\
\hline IV & 44 & 6,1 & 0,93 & 81,6 & $\|$ & 79 & 9,8 & 0,58 & 51,0 \\
\hline
\end{tabular}

A²SBS : activated anaerobic sludge blanket system com mistura mecânica; A²SBS: activated anaerobic sludge blanket system por jatos intermitentes; TDH: tempo de detenção hidráulica; $V_{a}$ : velocidade ascensional; TAS: taxa de aplicação superficial no sedimentador; TDH: tempo de detenção hidráulica. Fonte: elaborada pelos autores.

\section{RESULTADOS E DISCUSSÃO}

$\mathrm{Na}$ Tabela 3, apresenta-se um resumo da eficiência global dos sistemas e das características do efluente final (após o sedimentador de alta taxa).

No $\mathrm{A}^{2} \mathrm{SBS}_{\mathrm{m}}$ a SST junto ao fundo dos reatores variou na faixa (preponderantemente) de 6,5 a $11,0 \%$, e, no outro caso $\left(\mathrm{A}^{2} \mathrm{SBS}_{\mathrm{j}}\right.$ ), de 2,5 a $9,0 \%$. Destaque-se que os valores de 11 e $9,0 \%$ foram pontos extremos, que ocorreram apenas uma vez.

Para o sistema $\mathrm{A}^{2} \mathrm{SBS}_{\mathrm{m}}$ foram determinadas as condições médias de todo o período experimental. Isso foi possível pelo fato de o sistema ter apresentado desempenho relativamente estável em todo o período, o que não ocorreu com o sistema $\mathrm{A}^{2} \mathrm{SBS}$. Constatou-se a potencialidade do uso da agitação por jatos, porém há necessidade de novas pesquisas.

Para que fosse possível a comparação entre os resultados de eficiência obtidos nesta pesquisa com os resultados médios encontrados em reatores UASB convencionais em operação, foi elaborado levantamento baseado em trabalhos amplos de diferentes autores.

Para isso, foram consolidados dados médios de levantamentos efetuados por:

i) Alberts et al. (1993), em várias ETE de Índia, Holanda, Colômbia e Brasil;

ii) Passig (2005), em ETE no Brasil;

iii) Elmitwalli (2013), baseado em 32 diferentes ETE de diversos países;

iv) Silva (2015) em ETE de Colômbia (2), Brasil (7), Índia (5) e países árabes.

A síntese desses resultados consta nas colunas I e II da Tabela 4, em que também são apresentados resultados das pesquisas objeto deste trabalho (colunas III a IV).

É importante destacar que atualmente existem milhares de reatores UASB em operação tratando esgoto sanitário em diferentes cenários. Uma amostra significativa teria de ter, então, centenas de reatores analisados e, ainda, separados em grupos com as mesmas características: porte, temperatura, concentração de matéria orgânica etc.

Ainda, com o objetivo de comparar os resultados desta pesquisa com o de reatores UASB convencionais, cita-se trabalho de Noyola (2004), que compilou o desempenho de 15 reatores UASB em operação (Índia, Brasil e Emirados Árabes) com capacidade para tratar de 3.048 a $164.000 \mathrm{~m}^{3} \mathrm{dia}^{-1}$. Em média, foram constatados os valores de concentração no efluente e de porcentagem de remoção citados a seguir:

i) demanda bioquímica de oxigênio (DBO): $89 \mathrm{mgL}^{-1}(62 \%)$;

ii) DQO: $233 \mathrm{mgL}^{-1}(58 \%)$;

iii) SST: $122 \mathrm{mgL}^{-1}(58 \%)$.
Adicionalmente, cita-se artigo de Oliveira e Von Sperling (2011), em que se avaliou o desempenho de alguns reatores UASB no Brasil. Entre outras conclusões, constatou-se que:

i) em $30 \%$ dos casos, a DBO do efluente superava $100 \mathrm{mgL}^{-1}$;

ii) em $50 \%$ dos casos, a DQO superava $270 \mathrm{mgL}^{-1}$;

iii) em $40 \%$ dos casos, o teor de SST superava $100 \mathrm{mgL}^{-1}$.

Levando-se em consideração o conjunto de dados da Tabela 4 e os levantamentos de Noyola (2004) e de Oliveira e Von Sperling (2011), conclui-se que o sistema $\mathrm{A}^{2} \mathrm{SBS}_{\mathrm{m}}$ com mistura mecânica apresentou resultados melhores do que reatores UASB convencionais.

Contudo, o melhor desempenho do $\mathrm{A}^{2} \mathrm{SBS}$ fica mais destacado, ainda, quando se comparam valores de TRC. Em artigo de Van Haandel e Lettinga (1999) é expresso que o TRC, em reatores UASB, deve estar entre 50 e 100 dias, embora haja reatores com valor de TRC menor que 50 dias. Segundo Santos, Chaves e Haandel (2016):

i) a idade do lodo é parâmetro fundamental para descrever o desempenho de reatores UASB;

ii) quanto menor a idade do lodo, maior será a fração de DQO no efluente e no lodo em excesso;

iii) a idade do lodo é fortemente dependente da eficiência do dispositivo de retenção de sólidos no UASB.

Nesse mesmo artigo, os autores supracitados relatam o uso de decantação lamelar sobreposta aos separadores GLS em um reator piloto $\left(1,2 \mathrm{~m}^{3}\right)$, cobrindo toda a área superficial e mantendo os GLS. Com TDH de 8 horas, o UASB convencional apresentou TRC igual a 58 dias, ao passo que naquele com decantação laminar foi atingido o TRC de 120 dias.

Na presente pesquisa e considerando-se o sistema $\mathrm{A}^{2} \mathrm{SBS}_{\mathrm{m}}$ quando operado com TDH de 8,2 horas $\left(\mathrm{V}_{\mathrm{a}}: 0,69 \mathrm{mh}^{-1}\right)$, o TRC médio foi de 175 dias, e, para TDH de 11,0 horas $\left(\mathrm{V}_{\mathrm{a}}: 0,52 \mathrm{mh}^{-1}\right)$, o TRC resultou em 220 dias.

Esses valores são muito superiores ao que se verifica em reatores UASB tradicionais e comprovam que a capacidade de retenção de sólidos suspensos nesta concepção, com decantação lamelar, é muito maior do que a que ocorre com os separadores GLS tradicionais.

No que se refere à manta de lodo, houve plena convergência dos resultados desta pesquisa com o que ocorre em reatores do tipo UASB convencional, tomando-se como referência o que consta em Agricultural University of Wageningen (1994), o que demonstra que os dispositivos de mistura empregados 
Tabela 3 - Eficiência global do sistema activated anaerobic sludge blanket system e características médias do efluente final.

\begin{tabular}{|c|c|c|c|c|c|c|c|c|c|c|c|c|c|}
\hline \multicolumn{7}{|c|}{ A²BR $_{\mathrm{m}}$ (agitação mecânica) } & \multicolumn{7}{|c|}{ A²SBR (agitação por jatos) } \\
\hline \multirow[t]{2}{*}{ Fase } & \multicolumn{3}{|c|}{ Eficiência\% } & \multicolumn{3}{|c|}{$\begin{array}{l}\text { Efluente final } \\
\qquad\left(\mathrm{mgL}^{-1}\right)\end{array}$} & \multirow{2}{*}{ Fase } & \multicolumn{3}{|c|}{ Eficiência\% } & \multicolumn{3}{|c|}{$\begin{array}{l}\text { Efluente final } \\
\qquad\left(\mathrm{mgL}^{-1}\right)\end{array}$} \\
\hline & DBO & DQO & SST & DBO & DQO & SST & & DBO & DQO & SST & $\mathrm{DBO}$ & DQO & SST \\
\hline I & - & 61 & 77 & - & 126 & 28 & \multirow{3}{*}{1} & \multirow{3}{*}{\multicolumn{6}{|c|}{$\begin{array}{c}\text { Esta fase estendeu-se por seis meses, com testes de TDH de 12,8, 10,3, } \\
86 \text { e 6,7 horas no reator biológico. Também foram feitos testes com } \\
\text { e sem recirculação do lodo. Como não foi possível alcançar equilíbrio } \\
\text { dinâmico nesse período experimental, esses resultados são omitidos } \\
\text { neste artigo. }\end{array}$}} \\
\hline II & 82 & 63 & 66 & 30 & 120 & 42 & & & & & & & \\
\hline III & 72 & 58 & 74 & 62 & 117 & 32 & & & & & & & \\
\hline IV & 78 & 72 & 78 & 51 & 122 & 34 & $\|$ & 71 & 53 & 47 & 60 & 153 & 59 \\
\hline
\end{tabular}

A²SBS: activated anaerobic sludge blanket system com mistura mecânica; A²SBS: activated anaerobic sludge blanket system por jatos intermitentes; DBO: demanda bioquímica de oxigênio; DQO: demanda química de oxigênio; SST: sólidos suspensos totais; TDH: tempo de detenção hidráulica. Fonte: elaborada pelos autores.

puderam ser operados (baixos valores de G) sem danos à distribuição do lodo no perfil vertical do $R$.

Com relação ao desempenho do decantador lamelar, notou-se que a remoção de sólidos suspensos foi bastante estável, variando na faixa de 89,4 a 97,0\%, e foi crescente em relação aos valores de TAS, alcançando seu máximo valor (97,0\% de remoção) quando a taxa de aplicação superficial foi estabelecida em $81,6 \mathrm{~m}^{3} \mathrm{~m}^{-2} \mathrm{dia}^{-1}$. A concentração média de sólidos suspensos no afluente (efluente do R) foi inferior a $400 \mathrm{mgL}^{-1}$ nas três fases iniciais de operação, porém elevou-se a $1137 \mathrm{mgL}^{-1}$ quando a $\mathrm{V}_{\mathrm{a}}$ foi elevada de 0,69 para $0,93 \mathrm{mh}^{-1}$ no R. Essa concentração (1137 $\left.\mathrm{mgL}^{-1}\right)$, entretanto, foi facilmente assimilada no decantador, e constatou-se até mesmo que houve aumento na eficiência de remoção dos sólidos. É importante destacar que o efluente do R, mesmo sem GLS, apresentou concentrações de sólidos suspensos plenamente aceitáveis para o decantador lamelar, o que permite concluir que o sistema GLS pode ser suprimido.

Houve presença de material flutuante no decantador, o que implica a necessidade de se terem dispositivos para sua remoção. Contudo, essa necessidade é consequência da eliminação do problema interno dos reatores UASB (escuma flutuante), porém em grau de dificuldade muito menor, pois a área efetivamente coberta pelos módulos do decantador é da ordem de $20 \%$ da área do reator UASB. A programação temporal da recirculação e a configuração do decantador devem ser estabelecidas de forma que ocorra o adensamento do lodo. Para ETE de pequeno porte, poder-se-á usar poço de lodo tronco-piramidal, porém nos de grande porte haverá necessidade de raspador de lodo sedimentado. A concentração de SST no lodo sedimentado é menor que a do lodo descartado do reator UASB. Assim, haverá aumento do volume a ser destinado ao desaguamento, porém a massa total de sólidos será menor no caso dos $\mathrm{A}^{2} \mathrm{SBS}$ pelo fato de eles terem seu TRC muito maior do que o dos UASB. Em decorrência disso, a massa e o volume do lodo desaguado a ser afastado da estação de tratamento será menor para o $\mathrm{A}^{2} \mathrm{SBS}$.

Durante toda a pesquisa, a concentração média de SST no efluente do decantador $\left(\mathrm{A}^{2} \mathrm{SBS} \mathrm{m}_{\mathrm{m}}\right.$ ) variou na faixa de 28 a $42 \mathrm{mgL}^{-1}$, e, surpreendentemente, a relação SSV/SST, na maior parte do tempo, superou o valor de 0,90 . Isso demonstra excelente remoção de sólidos suspensos fixos e arraste somente de partículas leves, predominantemente orgânicas.

Como um dos questionamentos que podem ocorrer se refere ao consumo adicional de energia elétrica, apresenta-se, a seguir, um exemplo hipotético para um sistema $\mathrm{A}^{2} \mathrm{SBS}_{\mathrm{m}}$ para atender população de cerca de 200 mil habitantes. Dados: vazão média: $44.000 \mathrm{~m}^{3} \mathrm{dia}^{-1}$; volume total dos reatores de manta de lodo: $15.000 \mathrm{~m}^{3}$; recirculação com conjunto motobomba afogado com eficiência de $67 \%$ e altura monométrica de $\left.6 \mathrm{mca}\left(\mathrm{Q}_{\mathrm{R}} / \mathrm{Q}=5,0 \%\right): 2.200 \mathrm{~m}^{2} \mathrm{dia}, 26 \mathrm{Ls}^{-1}\right) \mathrm{e}$ energia efetivamente dissipada no reator decorrente da agitação: $0,118 \mathrm{Wm}^{-3}$ $\left(\mathrm{G}=10 \mathrm{~s}^{-1}\right)$ operando 4,25 h.dia ${ }^{-1}$, custo do $\mathrm{kWh}: \mathrm{R} \$ 0,65$, valor do dólar: $\mathrm{R} \$ 5,59$ (9 de outubro de 2020). Foi considerado coeficiente multiplicador igual a 3,0 referente à segurança e perdas adicionais em redutores etc. Nessas condições, as demandas de energia e o custo por dia serão:

i) recirculação: $167,4 \mathrm{hWhdia}^{-1} ; \mathrm{R} \$ 108,80 \mathrm{dia}^{-1}$;

ii) para a mistura: $22,6 \mathrm{hWhdia}^{-1} ; \mathrm{R} \$ 14,69 \mathrm{dia}^{-1}$. Total: $190 \mathrm{kWhdia}{ }^{-1}$ e R\$ $123,50 \mathrm{dia}^{-1}$

Custo por metro cúbico tratado: $\mathrm{R} \$ 0,003 \mathrm{~m}^{-3}\left(\mathrm{U} \$ 0,0005 \mathrm{~m}^{-3}\right)$. Após essas estimativas, não seria arriscado afirmar que o aumento no custo do esgoto tratado (comparando-se com os reatores UASB: gasto zero de energia) no $\mathrm{A}^{2} \mathrm{SBS}_{\mathrm{m}}$ seria da ordem de um centavo de Real por $\mathrm{m}^{3}$, mesmo considerando-se o consumo dos raspadores dos decantadores (baixa potência). No caso do $\mathrm{A}^{2} \mathrm{SBS}_{\mathrm{i}}$ os custos seriam ainda menores.

\section{CONCLUSÕES}

- A concepção proposta neste trabalho, que constitui um sistema anaeróbio de lodo ativado com reator de manta de lodo ( $\mathrm{A}^{2} \mathrm{SBS}$ ), constituído de um reator de manta de lodo sem separador trifásico e com decantador lamelar e recirculação de lodo sedimentado, mostrou-se tecnicamente viável e com desempenho superior ao de reatores UASB convencionais. Essa conclusão decorre, principalmente, do fato de o TRC no $\mathrm{A}^{2} \mathrm{SBS}$ resultar muito superior aos valores obtidos em reatores UASB - de 50 até 100 dias, segundo Von Haandel e Lettinga (1994). Para TDH de 8,2 horas e $V_{a}$ de 0,69 $\mathrm{mh}^{-1}$ (na manta de lodo), por exemplo, o TRC obtido para o $\mathrm{A}^{2} \mathrm{SBS}$ foi de 175 dias. Para valores de $\mathrm{V}_{\mathrm{a}}$ menores, ocorreram valores ainda maiores de TRC. Sendo o TRC muito maior no $\mathrm{A}^{2} \mathrm{SBS}$, como consequência natural, ocorrem maior retenção de sólidos, maior eficiência na degradação de matéria orgânica e maior produção de biogás.

- Os tradicionais separadores trifásicos (GLS) de reatores com manta de lodo - e, como consequência, também do sistema de remoção de escuma - podem ser eliminados, empregando-se como substituição a decantação lamelar para a remoção dos SST do efluente da zona de reação. Nesta pesquisa a relação entre a área efetivamente coberta por módulos e a área superficial do $\mathrm{R}$ foi da ordem de 0,20 , e a maior taxa de aplicação superficial testada no decantador lamelar foi de $81,6 \mathrm{~m}^{3} \mathrm{~m}^{-2} \mathrm{dia}^{-1}$. Nas condições mais 
extremas de operação $\left(81,6 \mathrm{~m}^{3} \mathrm{~m}^{-2} \mathrm{dia}^{-1}\right)$, a remoção média de SST foi de $97,0 \%$ no decantador SST (média no afluente do decantador de $1137 \mathrm{mgL}^{-1}$, que corresponde ao efluente da zona de reação) com $\mathrm{V}_{\mathrm{a}}$ de $0,93 \mathrm{mh}^{-1}$ (na zona de reação). Durante toda a etapa experimental a concentração de SST no efluente do decantador não superou $42 \mathrm{mgL}^{-1}$ e a mínima eficiência de remoção foi de $89,4 \%$ em todo o período experimental, quando se usou agitação mecânica. Além disso a relação SSV/SST, para a maior parte de tempo no efluente, foi superior a 0,90 . Na fase monitorada do sistema com agitação por jatos, essa concentração foi de $59 \mathrm{mgL}^{-1}$. Esses valores raramente são constatados para reatores UASB convencionais.

- Os resultados com agitação mecânica da zona de reação demonstraram que é possível manter a manta de lodo com a mesma configuração daquela que ocorre em reatores UASB - que é quesito fundamental no sistema $\mathrm{A}^{2} \mathrm{SBS}$. Esses resultados sugerem que se devem aplicar valores adicionais bastante baixos de gradiente de velocidade e com operação intermitente. Nesta pesquisa, foram empregados os critérios: $\mathrm{G}$ médio: $2,5 \mathrm{~s}^{-1}$; e ciclos operacionais do equipamento: parado $17 \mathrm{~min}$, operando $3 \mathrm{~min}$. No que se refere à mistura com jatos intermitentes, constatou-se, também, a viabilidade técnica (manutenção de manta tradicional), contudo sem se chegar a conclusões seguras com relação ao desempenho do sistema. Há necessidade de novas pesquisas.

- A agitação mecânica permite flexibilidade operacional no que concerne à variação do gradiente de velocidade $\mathrm{G}\left(\mathrm{s}^{-1}\right)$ na manta de lodo, o que por sua vez (agitação) tem influência na produção de biogás e na remoção de matéria orgânica. Assim, essa providência pode constituir um recurso a mais quando se deseja a otimização do processo na zona de reação, bastando para isso pequenas alterações na rotação do agitador. A existência de equipamento inserido na manta para prover melhor mistura permite que o número de pontos de alimentação do afluente junto ao fundo da zona de reação seja diminuído consideravelmente. Mistura com baixa intensidade pode melhorar o adensamento do lodo.

- Por se tratar de um sistema de lodo ativado, a recirculação do lodo sedimentado no decantador lamelar é obrigatória. Nesta pesquisa, a relação entre vazão de lodo recirculado e vazão média do afluente no $\mathrm{A}^{2} \mathrm{SBRS}_{\mathrm{m}}$ variou na faixa de 2,1 a 5,0\%, com concentração de SST média de 2,65\%. O fundo do decantador lamelar e a recirculação devem ser concebidos para se conseguir o máximo adensamento do lodo. Assim, a recirculação deverá ser intermitente para viabilizar o adensamento do lodo. Outra forma operacional alternativa seria a de recircular todo o lodo sedimentado e efetuar descarte de lodo diretamente do R.

- Conforme demonstrado no texto deste artigo, o consumo adicional de energia (comparando-se com reatores UASB) é pequeno, da ordem de apenas um centavo de Real (9 de outubro de 2020) por metro cúbico de esgoto tratado. Quando se usa agitação com jatos, esse custo é ainda menor.

- A agitação adicional traz benefício para a melhoria da mistura e a flexibilidade operacional. Contudo, o uso do conceito do $\mathrm{A}^{2} \mathrm{SBS}$ pode ser aplicado a reatores anaeróbios de manta de lodo sem agitação adicional, desde que se respeitem os critérios adequados para a manta de lodo observados para reatores UASB. Também, nesse caso, pode-se usar decantador lamelar e não se usarem os GLS e o sistema de remoção de escuma no R.

- Considerando-se que os reatores UASB convencionais têm quase a metade de seu volume ocupado pelo separador de fases (GLS) e zona de decantação, certamente pesquisas futuras podem levar à possibilidade de redução da altura do reator, desde que se mantenha elevado valor de TRC e se respeitem os limites da velocidade ascensional junto ao fundo da unidade.

\section{AGRADECIMENTOS}

Esta pesquisa recebeu o apoio da Fundação para o Amparo da Pesquisa do Estado de São Paulo — FAPESP (Processo 10/518245), do Conselho Nacional de Pesquisa e do Aperfeiçoamento Tecnológico - CNPq (Processo 304151/2010-6) e da Coordenação de Aperfeiçoamento de Pessoal do Ensino Superior - CAPES.

\section{CONTRIBUIÇÃO DOS AUTORES}

Campos, J. R.: conceituação, curadoria de dados, metodologia, análise formal, escrita - primeira redação —, supervisão, obtenção de financiamento. Pessotto, B.: metodologia, elaboração dos desenhos técnicos. Borges, N. B.: análise formal, escrita - revisão e edição.

\section{REFERÊNCIAS}

ASSOCIAÇÃO BRASILEIRA DE NORMAS TÉCNICAS (ABNT). Elaboração de projetos hidráulico-sanitários de estações de tratamento de esgotos sanitários - NBR 12.209. Rio de Janeiro: ABNT, 2011.53 p.

AGRICULTURAL UNIVERSITY OF WAGENINGEN. Manual for the design, construction, operation and maintenance of UASB treatment plants for domestic wastewater. A2820.24/R16A/WMW/JLH. Directorate General of International Cooperation (DGIS). Holland, 1994.50 p.

AIYUK, S.; FORREZ, I.; LIEVEN, K:; VAN HAANDEL, A.; WERSTRATE, W. Complementary treatment of domestic sewage in regions with hot climate: a review. Biosorce Technology, v. 97, n. 17, p. 2225-2241, 2006. https://doi. org/10.1016/j.biortech.2005.05.015
APHA; AWWA; WEF. Standard methods for the examination of water and wastewater. 22. ed. Washington: AWWA, 2012. 1496 p.

ALBERTS, G. J.; VEENSTRAT, S.; BENTVELSEN, M.; VANDUIJIL, L. A. Feasibility of anaerobic sewage treatment in sanitation strategies in developing countries. Water Science and Technology, v. 27, n. 1, p. 179-186, 1993. https:// doi.org/10.2166/wst.1993.0042

Atiemo-obeng, V. A.; PenNeY, W. R.; ARMENANTE, P. Solid-liquid mixing. In: PAUL, E. L.; ATIEMO-OBENG, V.; KRESTA, S. M. Handbook of industrial mixing: science and practice. Hoboken: John Wiley \& Sons, 2003. p. 543-584. 
AZEVEDO NETTO, J. M.; FERNANDEZ Y FERNANDEZ, M.; ARAUJO, R.; ITO, A. E. Manual de Hidráulica. 8. ed. São Paulo: Blücher, 1998. 669 p.

BORGES, N. B. Aproveitamento dos resíduos gerados no tratamento preliminar de estações de tratamento de esgoto. Tese (Doutorado em Engenharia Hidráulica e Saneamento) - Universidade de São Paulo, 2014. 240 p.

BRIDGEMAN, J. Computational fluid dynamics modelling of sewage sludge mixing in an anaerobic digester. Advances in Engineering Software, v. 44, p. 54-62, 2012. https://doi.org/10.1016/j.advengsoft.2011.05.037

CLEASBY, J. L. Is velocity gradient a valid turbulent flocculation parameter? Journal of Environmental Engineering, ASCE, v. 110, n. 5, p. 875-897, 1984. https://doi.org/10.1061/(asce)0733-9372(1984)110:5(875)

DAGUE, R. R.; MCKINNEY, R. E.; PFEFFER, J. T. Solids retention in anaerobic waste treatment systems. Journal of the Water Pollution Control Federation, v. 42, n. 2, p. R29-R46, 1970

DUTTA, A.; DAVIES, D.; IKUNI, D. S. Performance of upflow anaerobic sludge blanket (UASB) reactors and other anaerobic reactors configuration for wastewater treatment: a comparative review and critical updates. Journal Water Supply Research and Technology, v. 67, n. 8, p. 858-884, 2018. https:// doi.org/10.2166/aqua.2018.090

ELMITWALLI, T. Mathematical modeling of upflow anaerobic sludge blanket (UASB) reactor treating domestic wastewater. Water Science et Technology, v. 67, n. 1, p. 24-32, 2013. https://doi.org/10.2166/wst.2012.512

HAANDEL, A.; VAN DER LUBBE, J. G. M. Handbook of biological of wastewater treatment: design and optimization of activated sludge systems. 2. ed. London, UK: IWA Publishing, 2012. 770 p.

HAANDEL, A.; LETTINGA, G. Anaerobic sewage treatment a practical guide for regions of the hot climate. Chichester: John Willey \& Sons, 1994. 226 p.

HARNBY, N.; EDWARDS, M. F.; NIENOW, A. W. Mixing in the process industries. Butter-Heinemann, Digital Printing, 2001.

HAZEN, S. P.; CULP, L. G. Applying shallow depth sedimentation theory. Journal AWWA, v. 59, n. 9, p. 1134-1147, 1967. https://doi. org/10.1002/j.1551-8833.1967.tb03501.x

HEFFERNAN, B; VAN LIER, J. B.; VAN DER LUBBE, J. G. M. Performance review of large scale up-flow anaerobic sludge blanket treatment plants. Water Science and Technology, v. 63, n. 1, p. 100-107, 2011. https://doi. org/10.2166/wst.2011.017

KARIM, K.; HOFFMANN, R.; KLASSON, T.; ALDAHHAN, M. Anaerobic digestion of animal waste: waste strengh versus impact of mixing. Bioresource Technology, v. 96, n. 16, p. 1771-1781, 2005. https://doi. org/10.1016/j.biortech.2005.01.020

KARIYAMA, I. D.; ZHAI, Y.; WU, B. Influence of mixing on anaerobic digestion efficiency in stired tank digestors: a review. Water Research, v. 143, p. 503517, 2018. https://doi.org/10.1016/j.watres.2018.06.065

LENCASTRE, A. Manual de hidráulica geral. 1. ed. Lisboa: AEIST, 1957. 342 p.

LENG, D. E.; KATTI, S. S.; ATIEMO-OBENG, V. Industrial mixing technology. In: Albright, L. F. (Ed.). Albright's chemical engineering handbook. Beca Raton: CRC Press, 2008. p. 615-707.
LETTINGA, G.; VAN VELSEN, A. F. M.; HOBMA, S. W., DEZEUW, W.; KLAPWIJK A. Use of the upflow sludge blanket (USB reactor concept for biological wastewater treatment, especially for anaerobic treatment. Biotechnology and Bioengineering, v. 22, n. 4, p. 699-734, 1980. https://doi.org/10.1002/ bit.260220402

LETTINGA, G. Anaerobic digestion for energy saving and production. In: PALZ, W.; CHARTIER, P.; HALL, D. O. Energy from biomass. 1 $^{\text {st }}$ E. C. Conference Proceedings of the International Conference on Biomass. London: Applied Science Publishers, 1981. p. 264-277.

LETTINGA, G.; HULSHOFF POL, L. W. UASB process design for various types of wastewater. Water Science \& Technology, v. 24, n. 8, p. 87-107, 1991 https://doi.org/10.2166/wst.1991.0220

LEVENSPIEL, O. Engenharia das reações químicas. Trad. de Verônica M. A Calado. 3. ed. São Paulo: Edgard Blucher, 2000.

LOBATO, L. C.; BRESSANI-RIBEIRO, T.; SILVA, B. S.; FLOREZ, C. A. D.; NEVES P. N. P.; CHERNICHARO, C. A. L. Contribuição para o aprimoramento de projetos, construção e operação de reatores UASB aplicados ao tratamento de esgoto sanitário. Parte 3. Gerenciamento do lodo e escuma. Revista DAAE - edição especial, v. 214, n. 66, p. 30-55, 2018.

METCALF \& EDDY/AECOM. Tratamento de efluentes e recuperação de recursos. 5. ed. Trad. L. I. Hespanho e J. C. MIERZWA. Porto Alegre: AMGH Edit Ltda, 2016. 1980 p.

MIKI, M. K. 2010. Dilemas do UASB. Revista DAE, v. 58, n. 183, p. 25-37, 2010 https://doi.org/10.4322/dae.2014.052

MILLS, P. J. Minimization of energy imput requirements of an anaerobic digester. Agricultural Wastes, v. 1, n. 1, p. 57-66, 1979. https://doi. org/10.1016/0141-4607(79)90007-6

NADAIS, H.; CAPELA, I.; ARROJA, L.; DUARTE, A. Treatment of dairy wastewater in UASB reactor inoculated with flocculent biomass. Water $S$. A., v. 31, n. 4, p. 603-608, 2006. http://doi.org/10.4314/wsa.v31i4.5151

NOYOLA, A. Anaerobic digestion applied to municipal wastewater treatment: facts and limitations of adapted technology for Latin America. Proceedings of the Water Environment Federation, v. 1, n. 10, 2004. https:// doi.org/10.2175/193864704784131464

OLIVEIRA, S. C.; VON SPERLING, M. Performance evaluation of different wastewater treatment Technologies operating in a developing country. Journal of Water, Sanitation and Hygiene for Development, v. 1, n. 1, p. 37-56, 2011. https://doi.org/10.2166/washdev.2011.022

PASSIG, F. H. Reator anaeróbio hibrido para o tratamento de esgoto sanitário. São Carlos, SP, Brasil. Tese (Doutorado em Engenharia Hidráulica e Saneamento) - Universidade de São Paulo, São Carlos, SP, Brasil, 2005. $148 \mathrm{p}$.

REALI, M. A. P. Concepção e avaliação de um sistema compacto para tratamento de água para abastecimento utilizando processo de flotação por ar dissolvido e filtração com taxa declinante. 2 volumes. Tese (Doutorado em Engenharia Hidráulica e Saneamento) - Universidade de São Paulo, São Paulo, 1991. 373 p.

POL, L. H.; LETTINGA, G. New technologies for anaerobic wastewater treatment. Water Science Technology, v. 18, n. 12, p. 41-53, 1986. https://doi. org/10.2166/wst.1986.0162 
RICHTER, A. C. Água: métodos e tecnologia de tratamento. São Paulo: Ed. Blücher, 2009. $340 \mathrm{p}$

SANTOS, S. L.; CHAVES, S. R. M.; VAN HAANDEL, A. Influence of phase separator design in the performance of UASB reactors, treating municipal wastewater. Water S. A., v. 42, n. 2, p. 176-182, 2016. https://doi.org/10.4314/ wsa.v42i2.01

SILVA, F. J. A.; LIMA, M. G.; MENDONÇA, L. A. R.; GOMES, M. J. T. L. Septic tank combined with anaerobic filter and conventional UASB - results from full scale plants. Brazilian Journal of Chemical Engineering, v. 30, n. 1. p. 133-140, 2017. http://doi.org/10.1590/S0104-66322013000100015

SILVA, R. S. G. Concepção e avaliação do desempenho de um reator anaeróbio de manta de lodo dotado de agitação com jatos e decantador de alta taxa tratando esgoto sanitário. Tese (Doutorado em Engenharia Hidráulica e Saneamento) - Escola de Engenharia de São Carlos, Universidade de São Paulo, São Carlos, 2015. 140 p.

SMITH, P. C. Experimental methane production from animal excreta in pilot scale and farm-size units. Journal of Animal Science, v. 48, n. 1, p. 202-217, 1979. https://doi.org/10.2527/jas1979.481202x
SINDALL, R.; BRIDGEMAN, J.; CARLIELL-MAQUET, C. Velocity gradient as a tool to characterize the link-between mixing and biogás-production in anaerobic waste digesters. Water Science \& Technology, v. 67, n. 12, p. 28002806, 2013. http://doi.org/10.2166/wst.2013.206

VAN LIER, J. B.; VASHI, A.; VAN DER LUBBE, J. G. M.; HEFFERMAN, B. Anaerobic sewage treatment using UASB reactors: engineering and operational aspects. In: FANG, H. H. P. (Ed.). Environmental anaerobic technology: applications and new developments. London: Imperial College Press, 2010. p. 59-89.

YAO, K. M. Theoretical study of high rate sedimentation. Journal Water Pollution Control Federation, v. 42, n. 2, p. 218-228, 1970.

YAO, K. M. High rate settlers. In: Symposium of New-Methods of Water Treatment, CEPIS, Asunción, Paraguay, 1972. 29 p.

YAO, K. M. Design of high-rate settlers. Journal of the Environmental Engineering Division, v. 99, n. 5, p. 621-637, 1973. https://doi.org/10.1061/ jeegav.0000091 